\title{
An inferential study of the phenotype for the chromosome 15q24 microdeletion syndrome: a bootstrap analysis
}

Antonio Palazón-Bru, Dolores Ramírez-Prado, Ernesto Cortés, María S Aguilar-Segura, Vicente F Gil-Guillén

In January 2012 a review of the cases of chromosome 15q24 microdeletion syndrome was published. However this study did not include inferential statistics. The aims of the present study were to update the literature search and calculate confidence intervals for the prevalence of each phenotype using bootstrap methodology. Published case reports of patients with the syndrome that included detailed information about breakpoints and phenotype were sought and 36 were included. Deletions in megabase (Mb) pairs were determined to calculate the size of the interstitial deletion of the phenotypes studied in 2012. To determine confidence intervals for the prevalence of the phenotype and the interstitial loss, we used bootstrap methodology. Using the bootstrap percentiles method, we found wide variability in the prevalence of the different phenotypes (3-100\%). The mean interstitial deletion size was $2.72 \mathrm{Mb}$ (95\% Cl: 2.35-3.10 Mb). In comparison with our work, which expanded the literature search by 45 months, there were differences in the prevalence of $17 \%$ of the phenotypes, indicating that more studies are needed to analyze this rare disease. 
1 Authors: Antonio Palazón-Bru ${ }^{1,2}$, Dolores Ramírez-Prado ${ }^{3,4}$, Ernesto Cortés ${ }^{4}$, María Soledad

2 Aguilar-Segura ${ }^{4}$, Vicente Francisco Gil-Guillén ${ }^{1,2}$.

3 Institutions:

4 1: Clinical Medicine Department, Miguel Hernández University, San Juan de Alicante, Alicante, 5 Spain.

6 2: Research Unit, Elda Hospital, Elda, Alicante, Spain.

7 3: Clinical Analysis Department, Elda Hospital, Elda, Alicante, Spain.

8 4: Pharmacology, Pediatrics and Organic Chemistry Department, Miguel Hernández University,

9 San Juan de Alicante, Alicante, Spain.

11 Corresponding author: Prof. Antonio Palazón-Bru, PhD, Departament of Clinical Medicine,

12 Miguel Hernández University, Carretera de Valencia-Alicante S/N, San Juan de Alicante 03550,

13 Spain. Phone: +34 965919449. Fax: +34 965919450. E-mail: antonio.pb23@gmail.com 


\section{INTRODUCTION}

18 Chromosome 15q24 microdeletion syndrome is a rare disease that was first analyzed by Sharp et

19 al. in 2007, characterizing the phenotype and genotype of four patients with this syndrome

20 (Sharp et al., 2007). Since this publication, further papers have contributed new cases, providing

21 descriptive comparisons of the phenotype and genotype between the new case and those already

22 described (Klopocki et al., 2008; Marshall et al., 2008; Andrieux et al., 2009; El-Hattab et al.,

23 2009; Masurel-Paulet et al., 2009; Van Esch et al., 2009; El-Hattab et al., 2010; McInnes et al.,

24 2010; Ng et al., 2011; Brun et al., 2012; Mefford et al., 2012; Narumi et al., 2012; Samuelsson et

25 al., 2015). Five breakpoints (low-copy repeat [LCR] clusters) have been identified where the

26 majority of the microdeletions have occurred: LCR15q24A, LCR15q24B, LCR15q24C,

27 LCR15q24D, and LCR15q24E (Magoulas \& El-Hattab, 2012).

28 As a result of these reports, in January 2012 Magoulas and El-Hattab conducted a comprehensive review of the cases reported up to that time (Magoulas \& El-Hattab, 2012). In this review they descriptively analyzed the phenotypes of the patients with the syndrome, both in detail and in large groups. However, as this work did not include inferential statistics calculating the proportion of children with the different phenotypes with their confidence intervals $(\mathrm{CI})$, we conducted a study to update the literature search and to determine the corresponding ranges for each phenotype using bootstrap methodology. The results provide a better understanding of this rare condition. 
Study population

39 The population included all individuals with chromosome $15 q 24$ microdeletion syndrome.

40

41

42

43

44

\section{Study design and participants}

This pooled analysis study examined MEDLINE and Google Scholar databases for reported cases of patients with the syndrome, using the keywords $15 q 24$, deletion and microdeletion. The references in all the cases obtained were reviewed to detect possible studies not found in the databases analyzed, in order to collect all the papers that had been used as references to cases of the syndrome. This search was updated on September 29, 2015.

Starting with the second published case report, the authors compared the characteristics of their patients with the published cases (Klopocki et al., 2008; Marshall et al., 2008; Andrieux et al., 2009; El-Hattab et al., 2009; Masurel-Paulet et al., 2009; Van Esch et al., 2009; El-Hattab et al., 2010; McInnes et al., 2010; Ng et al., 2011; Brun et al., 2012; Mefford et al., 2012; Narumi et al., 2012; Samuelsson et al., 2015). We analyzed all the references in these case reports in order to obtain the maximum sample size.

\section{Variables and measurements}

First, we determined which children had each of these phenotypes: male gender, developmental delay, low birth weight/intrauterine growth restriction, short stature, obesity, microcephaly, feeding difficulties, long face, facial asymmetry, high anterior hairline, epicanthal folds, hypertelorism, downslanting palpebral fissures, sparse and broad medial eyebrows, strabismus, nystagmus, broad nasal base, depressed nasal bridge, high nasal bridge, ear abnormalities, palate abnormalities, long smooth philtrum, full lower lip, small mouth, hypospadias, microphallus, cryptorchidism, thumb abnormalities, brachydactyly/short digits, clynodactyly, toe 
60 abnormalities, joint laxity, scoliosis/kyphosis, hypotonia, behavior problems, magnetic resonance

61 imaging (MRI) abnormalities, recurrent infections, hernias, congenital heart disease, hearing

62 loss, diaphragmatic hernia, intestinal atresia, imperforate anus, coloboma, dental problems and

63 myelomeningocele. The phenotypes used followed the previous review (El-Hattab et al., 2010).

64 The deleted megabase $(\mathrm{Mb})$ pairs in each patient were determined to calculate the size of the

65 interstitial deletion of chromosome 15q24 (in Mb). Finally, we also analyzed the five breakpoints

66 (Magoulas \& El-Hattab, 2012).

67 The source of information was the selected papers, i.e., those containing complete information 68 on phenotype and genotype $(\mathrm{Mb})$.

\section{Sample size}

The sample size was 40 patients, 4 of whom were excluded due to lack of the information required for this study ( $\mathrm{Mb}$ and phenotype). The final sample consisted of 36 patients.

\section{Statistical methods}

The phenotype was described using absolute frequencies. One thousand bootstrap samples were obtained to determine the relative distribution frequency for the phenotypes and the mean loss size of the interstitial deletion of chromosome 15q24 (in Mb). Using these samples, we calculated a point estimate (median) and a CI (percentiles method) for these parameters (proportions and means). Thus we obtained a measurement of the uncertainty for the relative frequencies and for the mean, since with a small sample size we could not perform an asymptotic approximation of the normal distribution $(n=36)$. This bootstrap methodology was based on taking 1,000 simple random samples with replacement of the original sample. For each sample we calculated the statistic of interest (in our case proportions/means). At the end of the process 
82 we obtained 1,000 values for the statistic. In other words, we had a distribution of the statistic

83 from which we could then calculate its estimation (median) with its CI (P2.5 - P97.5). This

84 method is very useful for obtaining the CI for statistics which are difficult to calculate (no closed

85 form or with hypotheses which are not present). The computational cost is the only aspect of this

86 method that is inadequate, but as our sample was small, this was not a problem. This

87 methodology has already been applied with other rare diseases (Chiano \& Yates, 1994). All

88 analyses were performed with a significance level of 5\%. The statistical software used was IBM

89 SPSS Statistics 19.

\section{RESULTS}

92 Table 1 shows the descriptive and analytical features of all the patients found in the literature search. We highlight the wide variability in the prevalence of the different phenotypes (3-100\%).

94 The phenotype with the lowest prevalence was myelomeningocele, which was only present in one case, whereas developmental delay was common in all cases $(n=36)$. The mean interstitial deletion loss was $2.72 \mathrm{Mb}(95 \% \mathrm{CI}: 2.35-3.10 \mathrm{Mb})$. Regarding the five breakpoints, we obtained the following results (patients who presented the deletion at the breakpoint): A) 19 (0.53, 95\% CI: 0.36-0.69); B) B) 30 (0.83, 95\% CI: 0.69-0.94); C) $25(0.69,95 \% \mathrm{CI}: 0.56-0.86)$; D) D) $11(0.31$ 95\% CI: 0.17-0.47); and E) 9 (0.25, 95\% CI: 0.11-0.39).

\section{DISCUSSION}

\section{Summary}

103 This study updates the descriptive analysis of the different phenotypes conducted in 2012 
104 (Magoulas \& El-Hattab, 2012), and provides inferential information on a range of values within

105 which the true proportion of each phenotype in the study population can likely be found (95\% $106 \mathrm{CI})$.

107

108

109

110

111

112

113

114

115

116

117

118

119

120

121

122

\section{Strengths and limitations of the study}

The main strength of this study is that, for the first time, a measurement of the uncertainty of the proportion of each phenotype in the population has been obtained using inferential statistics (bootstrap samples). In addition, the descriptive data provided by Magoulas and El-Hattab (Magoulas \& El-Hattab, 2012) have also been updated.

Concerning the limitations of this study, we have to assume a possible selection bias, since it is possible that not all incident cases of this syndrome have been published or that in our search strategy we may not have found all recently published cases, as we did not include the DECIPHER and ECARUCA databases. To minimize this bias as much as possible, we rigorously reviewed all the references for each of the articles. In terms of reporting bias, it is possible that not all the features have been specified in each of the cases. For example, MRI abnormalities: not all reported patients would have had an MRI scan done. In those cases the statistics for MRI abnormalities would be difficult to derive. Regarding obesity, the other authors used the Z-score for its assessment. In other words, the researchers took into account the age and gender of the patients. Other features are largely descriptive (thumb abnormalities, hypertelorism and brachydatyly) and thus subject to single clinical observer bias. Finally, the information was obtained through the publications instead of by contacting the authors. For obvious reasons, this information bias cannot be minimized. If we were analyzing associations between phenotypes and genotypes, this bias could give us incorrect information about the associations. However, we 
126 only obtained descriptive statistics with their confidence interval using the original sample

127 through bootstrap methodology.

128 Comparison with the existing literature

129 To compare our results with those found by the 2012 study (Magoulas \& El-Hattab, 2012), we

130 determined whether the point estimate given by the previous study was within the CI we

131 constructed for each phenotype. Such that if the estimate of the other study fell within that range,

132 we had no evidence indicating that the proportion was different from that of our study (Magoulas

$133 \&$ El-Hattab, 2012). However, if this estimate fell outside our CI, there was a difference

134 compared with our study.

135 Overall we found agreement between both studies, as the previous estimate in nearly $83 \%$ of the

136 phenotypes (38/46) was within our CI. The eight phenotypes that showed discrepancies with the

137 previous study (Magoulas \& El-Hattab, 2012) were facial asymmetry, high anterior hairline,

138 hypertelorism, broad nasal base, hypospadias, microphallus, thumb abnormalities, and

139 clynodactyly, all of which were approximately twice as prevalent in the earlier study (Magoulas

$140 \&$ El-Hattab, 2012) than in our study. To assess the reasons for these discrepancies we need

141 further studies on this syndrome, because they cannot be determined using our study design.

142

143

144

145

146

147

\section{Implications for research and/or practice}

The comparative analysis between our results and those of the review published in 2012 (Magoulas \& El-Hattab, 2012) revealed differences in 17\% of the phenotypes. Given that the previous article was accepted for publication in January 2012 (Magoulas \& El-Hattab, 2012), and that our work expanded the literature analysis by approximately 45 months, it appears that the prevalence of the phenotypes in these patients is not fully known, which suggests the need 
148 for future studies in this rare syndrome. When there are more published cases of this rare

149 syndrome, it would be very interesting to determine associations between the phenotypes and the

150 size of the deletion. These associations were not studied in our paper because with 36 patients

151 we would not have been able to obtain valid conclusions. Finally, it would be interesting to

152 measure some phenotypes with facial recognition software (facial asymmetry, high anterior

153 hairline, hypertelorism and broad nasal base).

154 Once we have this new knowledge, we can devise strategies to improve our decisions regarding

155 these patients. For instance, we could attempt to determine where the breakpoint is using only

156 the information about the phenotype.

\section{CONCLUSIONS}

159 The prevalence of the different phenotypes in patients with chromosome $15 \mathrm{q} 24$ microdeletion 160 syndrome, published in early 2012 (Magoulas \& El-Hattab, 2012), has been updated. The CI 161 were calculated based on bootstrap samples for these proportions, providing a measurement of

162 the uncertainty in the study population. Furthermore, differences between our study and the 2012 163 study were found in approximately one in six phenotypes, which suggests more studies are 164 needed to analyze the characteristics of this rare syndrome.

167 We thank Maria Repice and Ian Johnstone for their help in preparing the English version of this 168 work. 
169

170

171

172

173

174

175

176

177

178

179

180

181

182

183

184

185

186

\section{REFERENCES}

Andrieux J, Dubourg C, Rio M, Attie-Bitach T, Delaby E, Mathieu M, Journel H, Copin H, Blondeel E, Doco-Fenzy M, Landais E, Delobel B, Odent S, Manouvrier-Hanu S, HolderEspinasse M. 2009. Genotype-phenotype correlation in four 15q24 deleted patients identified by array-CGH. American Journal of Medical Genetics Part A 149A:2813-2819.

Brun A, Cailley D, Toutain J, Bouron J, Arveiler B, Lacombe D, Goizet C, Rooryck C. 2012. 1.5 $\mathrm{Mb}$ microdeletion in $15 \mathrm{q} 24$ in a patient with mild OAVS phenotype. European Journal of Medical Genetics 55:135-139.

Chiano MN, Yates JR. 1994. Bootstrapping in human genetic linkage. Annals of Human Genetics 58(Pt 2):129-143.

El-Hattab AW, Smolarek TA, Walker ME, Schorry EK, Immken LL, Patel G, Abbott MA, Lanpher BC, Ou Z, Kang SH, Patel A, Scaglia F, Lupski JR, Cheung SW, Stankiewicz P. 2009. Redefined genomic architecture in $15 q 24$ directed by patient deletion/duplication breakpoint mapping. Human Genetics 126:589-602. 
187 El-Hattab AW, Zhang F, Maxim R, Christensen KM, Ward JC, Hines-Dowell S, Scaglia F,

188 Lupski JR, Cheung SW. 2010. Deletion and duplication of 15q24: molecular mechanisms and

189 potential modification by additional copy number variants. Genetics in Medicine 12:573-586.

190

191

192

193

194

195

196

197

198

199

200

201

202

203

204

205

206
Hanley JA, McNeil BJ. 1982. The meaning and use of the area under a receiver operating characteristic (ROC) curve. Radiology 143:29-36.

Hanley JA. 1989. Receiver operating characteristic (ROC) methodology: the state of the art. Critical Reviews in Diagnostic Imaging 29:307-335. Review.

Klopocki E, Graul-Neumann LM, Grieben U, Tönnies H, Ropers HH, Horn D, Mundlos S, Ullmann R. 2008. A further case of the recurrent 15q24 microdeletion syndrome, detected by array CGH. European Journal of Pediatrics 167:903-908.

L Ng IS, Chin WH, P Lim EC, Tan EC. 2011. An additional case of the recurrent 15q24.1 microdeletion syndrome and review of the literature. Twin Research and Human Genetics 14:333-339.

Magoulas PL, El-Hattab AW. 2012. Chromosome 15q24 microdeletion syndrome. Orphanet Journal of Rare Diseases 7:2. Review. 
Marshall CR, Noor A, Vincent JB, Lionel AC, Feuk L, Skaug J, Shago M, Moessner R, Pinto D,

Ren Y, Thiruvahindrapduram B, Fiebig A, Schreiber S, Friedman J, Ketelaars CE, Vos YJ,

Ficicioglu C, Kirkpatrick S, Nicolson R, Sloman L, Summers A, Gibbons CA, Teebi A, Chitayat

Roberts W, Fernandez B, Szatmari P, Scherer SW. 2008. Structural variation of chromosomes in autism spectrum disorder. American Journal of Human Genetics 82:477-488.

217 Journal of Human Hypertension 29:40-45.

Masurel-Paulet A, Callier P, Thauvin-Robinet C, Chouchane M, Mejean N, Marle N, Mosca AL,

Ben Salem D, Giroud M, Guibaud L, Huet F, Mugneret F, Faivre L. 2009. Multiple cysts of the corpus callosum and psychomotor delay in a patient with a $3.1 \mathrm{Mb} 15 \mathrm{q} 24.1 \mathrm{q} 24.2$ interstitial deletion identified by array-CGH. American Journal of Medical Genetics Part A 149A:15041510. 
227 the novel 15q24 microdeletion syndrome in autism spectrum disorders identifies an atypical

228 deletion that narrows the critical region. Molecular Autism 1:5.

Mefford HC, Rosenfeld JA, Shur N, Slavotinek AM, Cox VA, Hennekam RC, Firth HV, Willatt

L, Wheeler P, Morrow EM, Cook J, Sullivan R, Oh A, McDonald MT, Zonana J, Keller K, Hannibal MC, Ball S, Kussmann J, Gorski J, Zelewski S, Banks V, Smith W, Smith R, Paull L, delineation of the 15q24 microdeletion syndrome. Journal of Medical Genetics 49:110-118. American Journal of Medical Genetics Part A 158A:412-416.

Ramírez-Prado D, Palazón-Bru A, Folgado-de-la Rosa DM, Carbonell-Torregrosa MA, Martínez-Díaz AM, Gil-Guillén VF. 2015. Predictive models for all-cause and cardiovascular mortality in type 2 diabetic inpatients. A cohort study. International Journal of Clinical Practice 69:474-484. 
249 Sharp AJ, Selzer RR, Veltman JA, Gimelli S, Gimelli G, Striano P, Coppola A, Regan R, Price

250 SM, Knoers NV, Eis PS, Brunner HG, Hennekam RC, Knight SJ, de Vries BB, Zuffardi O,

251 Eichler EE. 2007. Characterization of a recurrent 15q24 microdeletion syndrome. Human

252 Molecular Genetics 16:567-572.

253

254 Van Esch H, Backx L, Pijkels E, Fryns JP. 2009. Congenital diaphragmatic hernia is part of the 255 new 15q24 microdeletion syndrome. European Journal of Medical Genetics 52:153-156. 


\section{Table $\mathbf{1}$ (on next page)}

Descriptive and analytical features of the phenotypes of the patients with chromosome $15 q 24$ microdeletion syndrome.

$\mathrm{Cl}$, confidence interval; IUGR, intrauterine growth restriction; MRI, magnetic resonance imaging; *, only for male gender. 


\begin{tabular}{|c|c|c|c|c|c|}
\hline Phenotype & $\begin{array}{l}\text { Total } \\
n=36\end{array}$ & $\begin{array}{c}\text { Proportion } \\
(95 \% \mathrm{CI})\end{array}$ & Phenotype & $\begin{array}{l}\text { Total } \\
n=36\end{array}$ & $\begin{array}{c}\text { Proportion } \\
(95 \% \mathrm{CI})\end{array}$ \\
\hline Male gender & 27 & $0.75(0.61-0.89)$ & Small mouth & 9 & $0.25(0.11-0.39)$ \\
\hline Developmental delay & 36 & $1(1-1)$ & Hypospadias & 9 & $0.25(0.11-0.39)$ \\
\hline Low birth weight/IUGR & 14 & $0.39(0.22-0.56)$ & Microphallus* & 5 & $0.19(0.04-0.36)$ \\
\hline Short stature & 11 & $0.31(0.17-0.47)$ & Cryptorchidism & 4 & $0.11(0.03-0.22)$ \\
\hline Obesity & 8 & $0.22(0.08-0.36)$ & Thumb abnormalities & 8 & $0.22(0.11-0.36)$ \\
\hline Microcephaly & 8 & $0.22(0.08-0.36)$ & Brachydactyly/short digits & 12 & $0.33(0.19-0.50)$ \\
\hline Feeding difficulties & 7 & $0.19(0.08-0.33)$ & Clynodactyly & 3 & $0.08(0.00-0.19)$ \\
\hline Long face & 9 & $0.25(0.11-0.42)$ & Toe abnormalities & 10 & $0.28(0.14-0.44)$ \\
\hline Facial asymmetry & 5 & $0.14(0.03-0.25)$ & Joint laxity & 14 & $0.39(0.22-0.56)$ \\
\hline High anterior hairline & 11 & $0.31(0.17-0.47)$ & Scoliosis/Kyphosis & 8 & $0.22(0.08-0.36)$ \\
\hline Epicanthal folds & 17 & $0.47(0.31-0.64)$ & Hypotonia & 18 & $0.50(0.33-0.64)$ \\
\hline Hypertelorism & 8 & $0.22(0.08-0.36)$ & Behavior problems & 16 & $0.44(0.28-0.58)$ \\
\hline Downslanting palpebral fissures & 15 & $0.42(0.25-0.58)$ & MRI abnormalities & 13 & $0.36(0.19-0.53)$ \\
\hline Sparse broad medial eyebrows & 15 & $0.42(0.25-0.58)$ & Recurrent infections & 11 & $0.31(0.17-0.44)$ \\
\hline Strabismus & 10 & $0.28(0.14-0.44)$ & Hernias & 5 & $0.14(0.03-0.28)$ \\
\hline Nystagmus & 3 & $0.08(0.00-0.19)$ & Congenital heart disease & 8 & $0.22(0.11-0.36)$ \\
\hline Broad nasal base & 5 & $0.14(0.03-0.25)$ & Hearing loss & 10 & $0.28(0.14-0.42)$ \\
\hline Depressed nasal bridge & 6 & $0.17(0.06-0.31)$ & Diaphragmatic hernia & 2 & $0.06(0.00-0.14)$ \\
\hline High nasal bridge & 2 & $0.06(0.00-0.14)$ & Intestinal atresia & 2 & $0.06(0.00-0.14)$ \\
\hline Ear abnormalities & 21 & $0.58(0.42-0.75)$ & Imperforate anus & 2 & $0.06(0.00-0.14)$ \\
\hline Palate abnormalities & 8 & $0.22(0.08-0.36)$ & Coloboma & 2 & $0.06(0.00-0.14)$ \\
\hline Long smooth philtrum & 15 & $0.42(0.25-0.58)$ & Dental problems & 3 & $0.08(0.00-0.19)$ \\
\hline Full lower lip & 9 & $0.25(0.14-0.42)$ & Myelomeningocele & 1 & $0.03(0.00-0.08)$ \\
\hline
\end{tabular}

